\section{Exploiting Fluorescent Reporter Molecules for Process Analytical Technology (PAT)}

Tobias Broger ${ }^{\mathrm{a}}$, Res P. Odermatt ${ }^{\mathrm{a}}$, Pablo Ledergerber ${ }^{\mathrm{b}}$, and Bernhard Sonnleitner*a

${ }^{*}$ Correspondence: Prof. Dr. B. Sonnleitnera Tel.: +41 5893454 92, E-mail: bern-

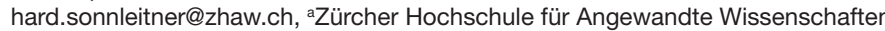
(ZHAW), Institut für Chemie und biologische Chemie (ICBC), Campus Reidbach Einsiedlerstasse 29, CH-8820 Wädenswil, 'Aquasant AG, Schartenstrasse 111, $\mathrm{CH}-5430$ Wettingen

\section{Abstract: Process Analytical Technology (PAT) launched by} the U.S. Food and Drug Administration (FDA) aims to ensure the quality of pharmaceutical products. One important tool to obtain a deeper process understanding is the use of modern real-time process sensors and analyzers. In this context an industrially accepted optical probe for turbidity measurement (Aquasant probe) has been adapted for on-line and realtime fluorescence measurement in (bio-)reactors. By tagging product proteins with fluorescent reporter molecules (e.g. GFP) it was possible to quantify product concentrations during a fermentation process with the new probe. The on-line obtained signal showed a high correlation to the off-line signal. This new method has remarkable advantages compared to classical off-line product lab analyses and can serve as a platformindependent quantification method of products to be used in either up- or downstream processing.

Keywords: Fluorescent tag · Fusion protein - Optical online sensor · Process analytical technology (PAT) · Real-time monitoring

\section{Introduction}

\subsection{The FDA-PAT Initiative}

The Process Analytical Technology (PAT) initiative launched by the U.S. Food and Drug Administration (FDA) aims to ensure the quality of pharmaceutical products (e.g. therapeutic proteins). Nowadays GMP (good manufacturing practice) with its blind compliance to fixed processes and quality by inspection approach is state-of-the-art. PAT promotes and encourages 'Quality by Design' achieved by a deeper process understanding through adaptive processes (http://www.fda.gov/Cder/OPS/PAT.htm). Important tools to reach this are among others:

i) modern real-time process analyzers (e.g. spectroscopic methods),

ii) continuous improvement and knowledge management and iii) multivariate data acquisition and analysis tools.

\subsection{Problem Identification}

The emergence of the genetic engineering since the seventies allows the large-scale manufacturing of heterologous proteins in bioreactor systems. Important factors during such a production process are i) the amount or titre, and ii) the productivity of recombinant target protein. Today's widely used protein analytical methods (e.g. SDS-PAGE, western-blot, MALDI-TOF) are offline, time- and cost-intensive, mostly non-quantitative and require human interactions. By tagging the target protein with a fluorescent reporter molecule (e.g. green fluorescent protein GFP) in addition to the common purification tag (Fig. 1), it is possible to draw conclusions about the product concentration by measuring the reporter specific fluorescence. GFP can be expressed in either prokaryotic or eukaryotic cells as a 'reporter molecule'. [1]

\subsection{In situ Fluorescence Measuring Principle}

A prerequisite in the difficult environment of the aerated and stirred bioreactor is a robust measuring method. First attempts to measure in situ fluorescence in bioreactors were made in the seventies using $\mathrm{NAD}(\mathrm{P}) \mathrm{H}$ as fluorophore ${ }^{[2-4]}$ resulting in the specific and stable, sterilisable NAD $(\mathrm{P}) \mathrm{H}$-dependent probe (Fluorosensor, Ingold, CH). ${ }^{[5]}$ Renders-Eichhorn et al. ${ }^{[6]}$ were the first, to our knowledge, to follow GFP-dependent fluorescence on-line in a bioreactor, showing that optical probes are able to quantify also the expression of fluorescent proteins on-line and in realtime. Further studies in in situ protein synthesis and production have been done with the rather complex and expensive BioView system (DELTA, DK) which allows 2D fluorescence spectra to be monitored. ${ }^{[7-10]}$

Our idea to make a less expensive and industrially accepted probe was to adapt the commercially available optical Aquasant probe which is well established in turbidity measurement ${ }^{[11-13]}$ for fluorescence measurement (Fig. 2). In this work, we show that this probe is able to determine fusion proteins quantitatively during a fermentation process by measuring the fluorescence of the co-expressed fluorescent reporter. We propose this technique as another contribution to PAT.

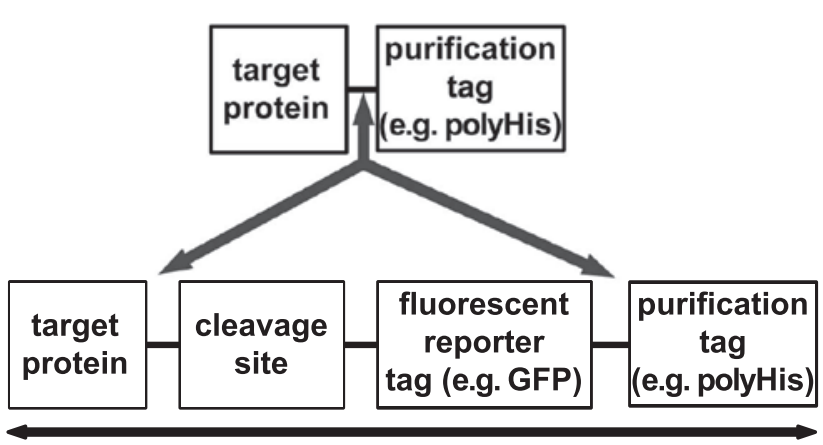

tagged fusion protein

Fig. 1. In addition to the common purification tag (top) a fluorescent reporter tag can be attached to the target protein and co-expressed. This enables the fusion protein (bottom) to be monitored through fluorescence measurement. At the end of the production process the target protein is released by cleavage with an appropriate enzyme.

\section{Experimental}

\subsection{Strains}

- Pichia pastoris GS115 Mut $^{+}$strain (methanol utilisation positive) with an eGFP (enhanced green fluorescent protein) and 


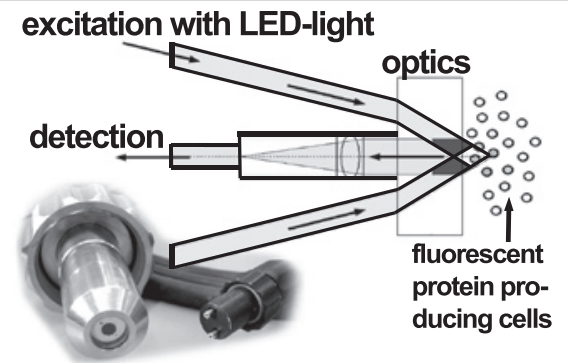

Fig. 2. Design of the modified Aquasant probe. The fluorophore specific excitation light is emitted by a LED. The emitted light is collected by precision optics and quantified in the detector. Both light beams are guided through two individual optical fibres. To minimize stray light effects the use of an optical filter in either light path is possible. The probe fits into a standard reactor port and is, of course, sterilisable.

His tagged target protein (confidential product protein, 100 $\mathrm{kDa}$ ) under the control of the AOX-promoter;

- Escherichia coli HMS174 expressing BFP (blue fluorescent protein); ${ }^{[7]}$

- Escherichia coli expressing HMS174 GFPmut3.1 (enhanced green fluorescent protein). [7]

\subsection{Fed-batch Cultivation of P. pastoris and On-line Fluorescence Measurement}

The studied $P$. pastoris strain producing an eGFP tagged fusion protein was grown in a 301 , computer-controlled, fully automated high performance bioreactor (Chemap) as described previously. ${ }^{[14]}$

eGFP fluorescence was measured on-line using an Aquasant prototype sensor (Aquasant AG, CH). A blue-green LED with an emission maximum at $470 \mathrm{~nm}$ (Winger Electronics $\mathrm{GmbH}, \mathrm{D}$ ) was used for excitation (for the determination of BFP and wild type GFP we recommend a violet LED with emission maximum at $398 \mathrm{~nm}$ ). For eGFP the excitation light was filtered by an optical low pass filter (Ocean Optics, USA) to cut off light above 500 $\mathrm{nm}$. The emission radiation, collected by the probe, was measured by an USB4000 miniature fibre optic spectrometer (Ocean Optics, USA). Data of continuous readings were averaged and logged every $5 \mathrm{~min}$.

\subsection{Off-line Fluorescence Measurement}

Off-line fluorescence intensities of reactor samples were measured with a Kontron fluorescence spectrophotometer model SFM25 (Kontron, $\mathrm{CH}$ ) at an excitation wavelength of $488 \mathrm{~nm}$ and emission wavelength of $512 \mathrm{~nm}$. 2D fluorescence spectra of cultures of the $E$. coli strains grown on defined glucose media ${ }^{[14]}$ were measured with a FluoroLog spectrofluorometer (Horiba Jobin Yvon, USA). To avoid matrix effects, off-line samples were diluted to an optical density of 0.5 at $600 \mathrm{~nm}$ before fluorescence measurement.

\section{Results and Discussion}

\subsection{On-line Target Protein Expression}

After a glycerol feeding phase (production of biomass), fusion protein expression in $P$. pastoris was induced by feeding methanol. Fig. 3 shows the on- and off-line fluorescence signals from induction through the duration of the fermentation. On-line measurements were those continuously monitored by the modified Aquasant fluorescence probe; off-line measurements were taken at irregular intervals. The trends of both signals are very similar. The correlation of the signals showed a linear relationship with an $\mathrm{r}^{2}$ of 0.98 . Western blot analysis and MALDI-TOF

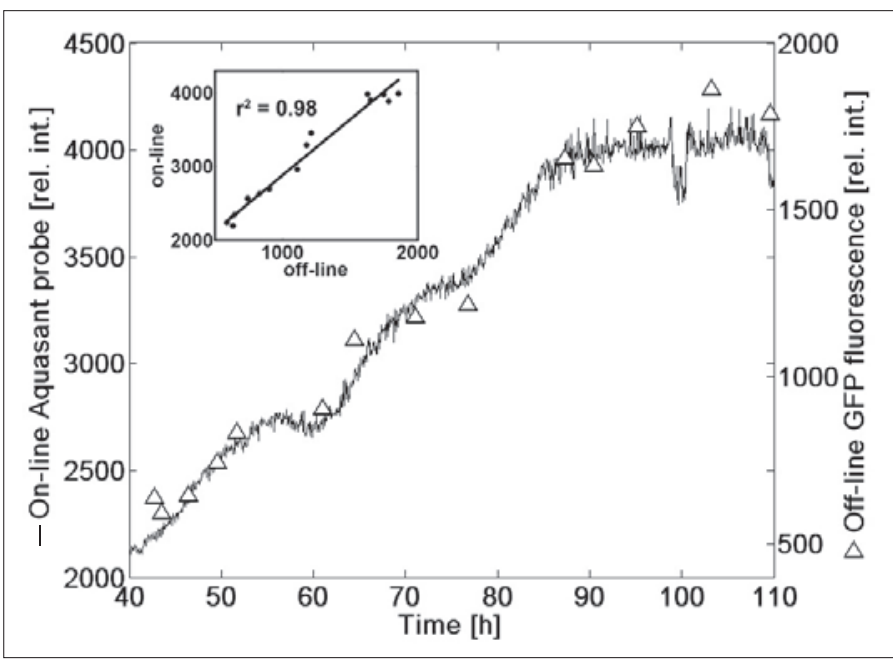

Fig. 3. Comparison of the on-line fluorescence signal (measured by the Aquasant probe) with off-line fluorescence analyses during the induction phase of a cultivation of $P$. pastoris producing an eGFP tagged protein. The on-line signal correlates almost perfectly with the off-line signal (correlation coefficient 0.98, see insert).

both confirmed the presence of the fusion protein at three different times during induction (data not shown).

DeLisa et al. ${ }^{[15]}$ were the first to show that there is a high correlation between chloramphenicol acetyltransferase (CAT) activity and GFP fluorescence when expressing both proteins as a fusion protein. Under this assumption, a quantitative estimation of the amount of target protein, which is often difficult to quantify, can be achieved in real-time.

\subsection{Comparison of On-line with Off-line Analysis}

Robust methods for the quantification of a target protein are very important for different purposes like: effective bioprocesses, process development, product identification, etc. Fluorescence tagging of the target protein is a powerful and inexpensive tool to draw conclusions to the amount of expressed target protein. The Table shows the advantages of fluorescent reporters over conventional analytical methods.

Table. Comparison of the fluorescent reporter on-line-measurement (using an appropriately modified Aquasant probe) with classical lab analyses.

\begin{tabular}{|c|c|c|}
\hline & $\begin{array}{l}\text { Fluorescent reporters } \\
\text { (FR) }\end{array}$ & $\begin{array}{l}\text { Classical lab } \\
\text { analytical methods } \\
\text { (e.g. SDS-PAGE, } \\
\text { Western blot) }\end{array}$ \\
\hline Time & real time, undelayed & $\begin{array}{l}\text { time consuming, } \\
\text { off-line }\end{array}$ \\
\hline Costs & $\begin{array}{l}\text { moderate investment, } \\
\text { very low } \\
\text { maintenance, } \\
\text { very low personal }\end{array}$ & $\begin{array}{l}\text { high costs } \\
\text { (consumables, } \\
\text { personal) }\end{array}$ \\
\hline Quantitative & yes & no \\
\hline Non-invasive & yes & no \\
\hline Closed loop control & yes & no \\
\hline
\end{tabular}

\subsection{Importance of Using the Right Fluorescent Tag}

Despite the many advantages of fluorescence tagging there are a few points to consider when using this method. The choice 


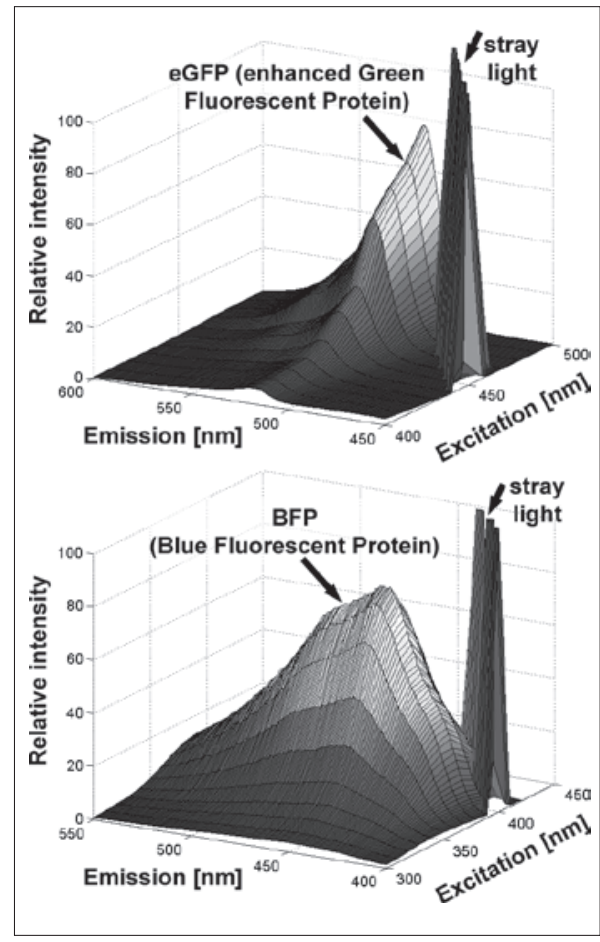

Fig. 4. 2D

fluorescence of $E$. coli suspensions expressing two different reporter proteins. The excitation/emission maxima of eGFP are very close to each other and therefore close to the stray light band which makes fluorescence measuring difficult while the excitation/ emission maxima of BFP are quite distant and, hence, isolated from the stray light band. Fluorescent reporters like BFP with a high difference between excitation and emission maxima are, therefore, preferable.

of the fluorescent tag is most important to get a robust and stable on-line signal. The strong aeration of the stirred suspension and its high turbidity results in massive backscattering of the excitation light and thus to a broad stray light band in the spectra. As shown in Fig. 4 stray light effects can be minimized by choosing a fluorophore with a high difference between excitation and emission wavelengths. Many fluorescent proteins are quite photostable and the exposure time to the excitation light is very short in the reactor. Therefore, influences of photo bleaching can be neglected.

An inexpensive and efficient method for the calibration of the probe is the use of chemical fluorophores with similar fluorescent characteristic to the according fluorescent protein (e.g. fluorescein for eGFP, quinine for BFP, ethacridine lactate for wtGFP).

\section{Conclusion and Outlook}

An on-line fluorescence sensor was designed and tested in the cultivation of a $P$. pastoris strain expressing an eGFP tagged target protein. The probe was able to monitor the fusion-protein production on-line and in real-time. A series of tests in measuring i) other fluorescent markers and ii) different strains (E. coli, Saccharomyces cerevisiae) have already shown promising results. A prototype sensor for standard bioreactor ports will soon be available on the market (Aquasant AG, CH). Further development of this sensor could allow the platform independent quantification of product proteins to be used in either upstream or downstream processing. In consideration of statistical methods the detector data could be used for multivariate data analysis in endpoint monitoring and fully automated closed loop control as a powerful PAT tool.

\section{Acknowledgements}

We greatly acknowledge the financial support of the Swiss Innovation Promotion Agency (CTI) and the Aquasant AG, Switzerland. We also gratefully acknowledge the laboratory of Prof. Karl Bayer at the University of Natural Resources and Applied Life Sciences in Vienna (Austria) for having kindly provided the recombinant E. coli strains. Further we thank Martin Brändli for the technical support in the lab and Jon Graf for the proof-reading.

Received: January 23, 2009

[1] M. Chalfie, Y. Tu, G. Euskirchen, W. W. Ward, D. C. Prasher, Science 1994 263,802 .

[2] D. E. Harrison, B. Chance, Appl. Microbiol. 1970, 19, 446.

[3] D. W. Zabriskie, A. E. Humphrey, Appl. Environ. Microbiol. 1978, 35 , 337.

[4] A. Einsele, D. L. Ristroph, A. E. Humphrey, Eur. J. Appl. Microbiol. Biotechnol. 1979, 6, 335

[5] W. Beyeler, A. Einsele, A. Fiechter, Eur. J. Appl. Microbiol. Biotechnol. 1981, 13,10 .

[6] L. Randers-Eichhorn, C. R. Albano, J. Sipior, W. E. Bentley, G. Rao, Biotechnol. Bioeng. 1997, 55, 921.

[7] H. Reischer, I. Schotola, G. Striedner, F. Pötschacher, K. Bayer, J Biotechnol. 2004, 108, 115 .

[8] J. J. Jones, A. M. Bridges, A. P. Fosberry, S. Gardner, R. R. Lowers, R. R. Newby, P. J. James, R. M. Hall, O. Jenkins, J. Biotechnol. 2004, 109, 201.

[9] S. Hisiger, M. Jolicoeur, J. Biotechnol., 2005, 117, 325.

[10] A. Surribas, D. Geissler, A. Gierse, T. Scheper, B. Hitzmann, J. L. Montesinos, F. Valero, J. Biotechnol. 2006, 124, 412.

[11] A. Nipkow, C. Andretta, O. Käppeli, Chem. Ing. Tech. 1990, 62, 1052.

[12] B. Sonnleitner, G. Locher, A. Fiechter, J. Biotechnol. 1992, 25, 5.

[13] D. Hongve, G. Akesson, Water Res. 1998, 32, 3143.

[14] B. Henes, B. Sonnleitner, J. Biotechnol. 2007, 132, 118.

[15] M. P. DeLisa, J. Li, G. Rao, W. A. Weigand, W. E. Bentley, Biotechnol. Bioeng. 1999, 65, 54 